hitherto considered so unimportant that they were eren not looked at in nine post mortems out of ten, produce such a train of symptoms as, in all well marked cases, have inrariably resulted in death? This question is still unsolved: Dr. Addison does not attempt an explanation; neither does the reporter in the Medical Times, who has collated all the recorded cases with the utmost caution and accuracy.

The reason of our ignorance on this point is patent. Before we can draw legitimate conclusions on the pathology of an organ, we must know its physiology; and here we are bound to confess our ignorance. Let us consult any or all the works on physiology within our reach, and we shall find little to enlighten us. According to some, the suprarenal capsules form one of a series of blood-perfecting organs, such as the spleen, the thyroid, and the thymusblood-glands without ducts, which are supposed to elaborate a something necessary to the due constitution of the vital fluid, which is at once reabsorbed. Among other and older writers there seemed to be a vague idea, but perhaps the truer one, that they are intimately associated with the nervous system, through the agency of the solar plexuses. But which, if either, is the correct view, we must at present leare in abeyance, satisfied simply with the fact, which is, I think, sufficiently established, that there is a disease marked by a certain train of symptoms during life, which, after death, exhibits a disease of the supra-renal capsules as the special lesion, to the exclusion of any disease of other organs which may not be accounted for by collateral morbid phenomena. And more than this has been ascertained; viz., that, in a large series of post mortem examinations instituted with reference to this very point, no disease has been found in these organs, where the peculiar train of symptoms in question has not existed.

What these symptoms are I will now briefly state, premising that they may occur in either sex, though generally, but not universally, after the middle period of life. These symptoms (I draw my description from a well marked instance) are, a gradual and almost imperceptible failure of strength, a gradual but not an extreme loss of flesh, a feeling of sinking in the epigastrium, constant nausea and indisposition to take food, depression of spirits, and failure in power without quickening of the circulation. At some indefinite period, the pathognomonic sign makes its appearance, in a peculiar discoloration of the skin, most marked on the exposed surfaces. This is unlike any other disccloration with which I am acquainted. It is not the pallor of chlorosis, the dirty sallow colour of the cancerous diathesis, or the yellow of jaundice; it is something sui generis. Once seen, it cannot fail to be recognised, and by this sign alone, perhaps some here present may call to mind cases which have previously been inexplicable to them. The colour is a peculiar dark coppery or bronzy hue, such as is seen in some oriental nations, very marked in the face and hands, less so on the body, and here varying in intensity, so as to give a patchy appearance. This symptom increases pari passi with the disease, as does also the inscrutable debility which resists every form of tonic and stimulant treatment. Pains in the joints resembling rheumatism are after a time superadded, and the patient gradually sinks; the liver, kidneys, and other emunctories, discharging their duties fully, until at last the patient becomes delirious or comatose, from sheer exhaustion, and dies.

But I cannot give a better idea of this disease than by the detail of the case to which I have alluded.

Case. The subject was a lady, aged 58 years, of remarkably tall and robust frame, and of great obesity previously to the commencement of her fatal illness. Iler habits of life were peculiar, especially in ber partiality for fatty matters, and her abstinence from farinaceous diet. She was also a considerable consumer of porter and wine. When she first consulted me, in August 1855, I was struck with the diminution of her bulk, and her great general prostration. Her chief complaint was of debility. Her appetite was bad, and she suffered from constant nausea and sinking at the pit of the stomach. She also incidentally called my attention to her colour, being particularly dissa- tisfied with the appearance of her hands, which resembled those of a creole. I confess that, on this occasion, I paid no attention to this apparently unimportant symptom, being interested only in the endeavour to discover a cause for the emaciation and exhaustion. I examined the heart, the lungs, and, on a subsequent occasion, the urine, without finding any such disease as could explain the nature of the case. The heart's action was feeble, and its sounds sharp; and the only conclusion I could come to at the time was, that I had a case of general decadence of the digestive powers from over-stimulation, together with fatty degeneration of the heart. The latter suspicion was borne out by the results of the post mortem examination.

She paid me several visits, but made no satisfactory progress; and the discoloration of the skin gradually deepened, perplexing me as much as it annoyed the patient. At this time I noticed the first of a series of cases publishing in the Medical Times, and I at once saw a clue to the enigma. I published the case at the time, and at once informed the friends of the peculiarity of the disease, and my conviction of its ultimate fatality. To be bricf, the progress was, with some fluctuations, daily for the worse; and, in the month of March, there were the additional symptoms of pains in the joints, neck, and limbs, which continued to the time of her death. In the latter two months of her life, she emaciated rapidly; and, in the final days, she had altcrnations of delirium and coma, the kidneys and bowels, howerer, acting naturally to the rery last.

The post mortem examination exhibited the following appearances. The body was emaciated. The integuments, especially the face and hands, were of a deep bronzy colour. The eyes were sunken; the conjunctivx pearly white. The subcutaneous fat, as well as that in the omentum and other internal parts, was firm, and of a deep chrome yellow. The head was not examined. The thoracic organs were healthy, with the exception of the heart, which was dilated, and in a state of fatty degeneration. The liver was softened, but otherwise healthy. The stomach was dilated, and its coats atrophied and destitute of rugæ. The spleen was of natural size and consistence. The intestines were healthy. The kidneys were congested and flabby. The supra-renal capsules were both enlarged, nodulated externally, and, when divided, were seen to be filled with tubercular deposit of various consistency, some portions being almost cartilaginous, others of the fluidity of scrofulous pus.

I have but little to add to this interesting case, further than to remark, that it offers onc of the most perfect specimens of the disease yet placed on record. I do not venture on an opinion as to its true pathology. Whether the disease in the supra-renal capsules is the fons et origo mali, or only the chief local manifestation of a new and general cachexia, remains yet to be proved. All that can be affirmed at present is, that the two facts are coincident, and that their conjunction is manifested by a train of symptoms against which medicine is inoperative.

\section{TREATMENT OF CONTRACTED NECK AFTER BURNS: THE ADVANTAGES OF THE SCREW \\ COLLAR IN THIS AND OTHER MALADIES.}

\section{By J. H. Jayes, Esq., Surgeon to the Devon and Exeter Hospital.}

Is the number of the Assocration Jodrsal for July 12th is the substance of a Clinical Lecture by Professor Quain, on the subject of Deformities of the Neck after Burns, in which is narrated a case, with illustrative engravings of an apparatus which in many respects much resembles that which I described in a paper published in the 13 th volume of the Medico-Chirurgical Transactions in the year 1825,* in which paper I endeavoured to show the true principles of treatment in those cases of contracted neck from burns

" "On the Treatment by a Now Method of Contracted Neck after Burna" 
able of rolief by our nich bere were considered incapable of rolief by our cham the importance be justly attaches to the subject, it lowe that the apparatus I described is very little known, oc the operation very little now practised in London ; $t$ for ftes otating that " the apparatus first applied was fixed on tho pelvis, and the extension was made with a strap beneath the chin, attached to a bar which paseed behind the spine and arched abore the head," he proceeds to say : "but that eontrivance was scarcely firm enough, and the child therefore slipped her head aside from it ; I therefore resolved on having an instrument to rest on the shoulders, and after Dr. Hillier had kindly searched in vain among the stores of our mechanicians for one likely to accomplish our object, I sent for Mr. Hainsley to construct one; his apparatus has fully answered my purpose." The engraving of the patient, taken two years afterwards, fully shows this; and it is gratifying to me to have this very unbiassed testimony from a surgeon of Mr. Quain's eminence, to the principles of an operation which I believe I am entitled to say, as regards the neck, originated with me.

In the memoir in the Medico-Chirurgical Transactions to which I have alluded, will be found a short history of three cases, with a rough sketch of the apparatus (which has since been improved), and of which an engraving is given in a Memoir published by my late friend Mr. Henry Earle, in the year 1832, in which he did me the honour to commend its use.

In the first case on which I operated, I endeavoured to prevent the recurrence of the contraction, by a power applied to draw back the head, on the same principle as Mr. Quain first adopted, but was baffled, as I believe will ever be the case, from the mobility of the cervical spine eluding the application of the power so employed; I therefore was led to think that it was necessary to have more fixed points d'appiri to counteract this, and these I considered to be the thorax below, and the head above. The success of the apparatus alluded to has since, in many cases which have occurred to my colleagues in this hospital as well as to myself, been complete; it not only preventing a recurrence of the contraction of the soft parts, but, by the gradual operation of the screw, redeeming the abnormal position of the bony structures which the firm tie of the cicatrix, especially when the subject was growing, had produced.

Mr. Quain apprehended, not without reason, that the contraction might return; he therefore did not publish his case until two years had elnpsed, and the permanence of the cure was in all probability ascertained.

I may now mention one case which, from the extreme character of the deformity, as well as from the long period which has elapsed, is still more important. It is that of a young woman from Cornwall, on whom I operated July 2nd, 1842 ; the deformity was fully as great as or more so than in the case delineated by Mr. Quain. The age (twenty-four) offered more difficulty; but the cure was certainly not less perfect, as is proved hy two casts, one taken before, the other after the operation, which are now in our Hospital Museum; these casts I took to Leeds, and showed at the meeting of the Provincial Association in August 1843. They were also seen by my friend Mr. Partridge, on my return through London; and he was so much struck with them, that he had copies taken and placed in the Museum of King's College. I may further add, that being much impressed with the importance of the method, I sent my casts and the apparatus to the Great Exhibition in 1851. Now, as regards this particular case, I am informed by my colleague Mr. Kempe (whose father originally sent the patient to me) that there has been no return of deformity; and I may say the same of another very bad case, Elizabeth Bulley, operated on by me in 1824, whom I myself saw lately.

The apparatus in question is not only useful in giving full effect to the operation for the removal of cicatrices in

+.I may likewise meition that in the three latest works of authority on general surgery by London surgeons, there is no notice +aken of it. I mean bo Bouch, Erichsen, and Druith the neck, but also in preventing their occurrence, if employed before these dense, unyielding structures are fully formed. It is also useful in cases of wry neck, whether to assist the operation, or to obviate the necessity for one; still more it is of the greatest value in cases of disease or injury of the cervical vertebroe, where a steady support to the head is required. In each description of case, I have derived great advantage from its employment; and it is, therefore, not so much for the purpose of showing that I had anticipated Mr. Quain in his views as regards the cure of these vicious cicatrices in the neck- - riews which he arrived at upon the same principles as myself, and without being aware of what I had done-as because it is my anxious endeavour to draw the attention of the profession to its more extensive use in the three other instances now stated.

Mechanical inventions in our art have, I conccive, in modern times, been too lightly esteemed by surgeons. For the most part, such inventions are founded upon as complete a knowledge of anatomy and the principles of surcery as any other branch of surgery, properly so speaking; and while they involve this knowledge to the fullest extent, they also imply readiness in adapting measures to remedy many most important evils. I am not a ware that the Council of the Royal College of Surgeons have adopted any measures calculated to encourage this part of our science; or that, in their vast Museum, any provision is made for the reception and record of instruments and apparatus which might serve mankind-the "Artes qua omnibus prosint," to use their own motto; but it is crident that the power of referring to such a collection would be of great value in many ways, and possibly the subject may receive the attention of the eminent men who form that Council.

July 21 st, $18 v 6$.

\section{CONSIDERATIONS RESPECTING THE OPERATION OF MALARIA ON THE HUMAN BODY.}

By C. Handfied Jones, M.B., F.R.S., Assistant-Physician to St. Mary's Hospital.

Iv the following remarks, I wish to draw attention to a cause of disease well known and appreciated in foreign lands, but in this country less considered than I beliere it ought to be. I refer to malaria; and I would say at once, that I do not mean to restrict the use of the term to the miasma produced by marshy lands, but to permit it a far wider application. What malaria may be in itself, we do not know-whether it be a chemical compound, a peculiar electrical state, or an allotropic form of common uatterbut we may say that it is distinct from the causes of typhus, typhoid, small-pox, or the other exanthemata; that it rather manifests relations of affinity with the causes of screral most common disorders; and that the conditions which give rise to it must be of rery common occurrence.

I proceed to notice briefly some of the most important points in the history of malaria, and then to consider at more length the diseases which it produces.

1. The almost universal prevalence of malaria throughout the temperate and tropical regions of the globe, is a circumstance, it appears to me, of the most striking import. Go almost where we will, to the fairest and brightest spots on the surface of the earth, the same evidence of the pronounced doom ever appears. Still it is found to be the case, "that cursed is the ground for thy sake". What is the country in Europe that is exempt from this scourge? As far north as Sweden it prevails; and the farther we proceed south the more intense and deadly does the poisonous influence become. From all the shores of the Moditerranean, we have accounts of its existence; and in Sicily, one of its islands, a non-medical authority has specified particularly no less than eighty-two unhealthy situations. It was probably one of these that a British com- 